\title{
Correction to: Goth Music and Depressive Symptoms among Adolescents: A Longitudinal Study
}

\author{
Tom ter Bogt $\mathbb{D}^{1} \cdot$ William W. Hale III $^{2} \cdot$ Natale Canale $^{3} \cdot$ Massimiliano Pastore $^{3} \cdot$ Alessio Vieno $^{3}$
}

Published online: 6 July 2021

(c) Springer Science+Business Media, LLC, part of Springer Nature 2021

Correction to: Journal of Youth and Adolescence (2020) https://doi.org/10.1007/s10964-020-01294-y

In the original publication of the article, the author noticed an error in the figure.

Figure 1 contains shaded regions that are not visible in the online publication. The corrected Fig. 1 is presented with this erratum.
The original article has been corrected.

Publisher's note Springer Nature remains neutral with regard to jurisdictional claims in published maps and institutional affiliations.

The original article can be found online at https://doi.org/10.1007/ s10964-020-01294-y.

Tom ter Bogt

t.f.m.terbogt@uu.nl

1 Department of Interdisciplinary Social Science, Utrecht University, Padualaan 14, $3584 \mathrm{CH}$ Utrecht, The Netherlands

2 Department of Pedagogics (Youth \& Family), Utrecht University, Heidelberglaan 1, 3584 CS Utrecht, The Netherlands

3 Department of Developmental Psychology and Socialisation, University of Padova, Via Venezia 8, 35131 Padova, Italy 
Fig. 1 Depressive symptoms as a function of liking Goth music (different lines) and years, separately for gender (different panels). Goth: $1=$ "Do not like at all" to 5 "Do like very much." The lines represent expected values of depressive symptoms on the basis of factor scores in the empirical data ranging from 0.008 to 4.89 . The shaded regions represent the $89 \%$ highest posterior density interval

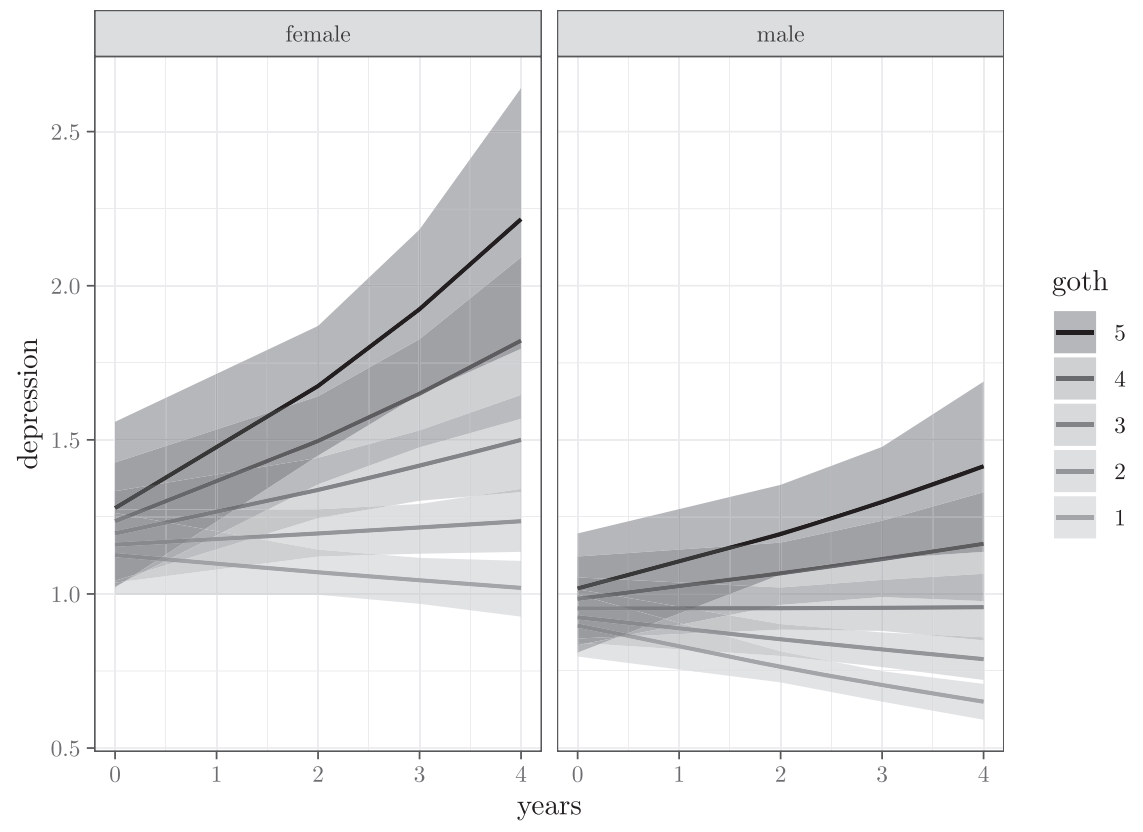

